\title{
Guest Editorial: SAICSIT 2016 extended papers
}

\author{
Carl Marnewick cmarnewick@uj.ac.za, \\ Duncan Coulter ${ }^{\mathrm{b}}$ dcoulter@uj.ac.za \\ a Department of Applied Information Systems, University of Johannesburg, South Africa \\ ${ }^{b}$ Academy of Computer Science and Software Engineering, University of Johannesburg, South Africa
}

\section{HOW PAPERS WERE SELECTED}

This special edition of the South African Computer Journal archives the best papers from the 2017 South African Institute of Computer Scientists and Information Technologists conference held at the University of Johannesburg from the 26th to the 28th of September 2016. Papers were selected from both the Computer Science and Information Systems streams according to their scores during the initial conference review process. Each paper was then sent for an additional round, or more, of double-blind peer-review.

\section{COMPUTER SCIENCE}

Within the Computer Science stream papers dealt with important topics from across the spectrum of disciplines within the field. These topics included investigating the increasing integration of computer generated spaces within the real world using mobile devices. Additionally the difficult topic of integrating several different biometric measurements into a single evaluation was considered and guidelines for the feature fusion process put forward. Lastly the use of procedural decision support systems was investigated for dealing with wicked problems.

\section{INFORMATION SYSTEMS}

The first article within the IS stream focuses on the challenges towards e-Government implementation in South Africa. This paper contributes to the ongoing discussion regarding the challenges facing e-government implementations in developing nations. It presents the outcomes of several discussions conducted with representatives from the municipal sector. The second paper focuses on

\footnotetext{
Marnewick, C. and Coulter, D. (2017). Guest Editorial: SAICSIT 2016 extended papers [Guest Editorial]. South African Computer Journal 29(1), 90-91. https://doi.org/10.18489/sacj.v29i1.520

Copyright (C) the author(s); published under a Creative Commons NonCommercial 4.0 License (CC BY-NC 4.0).

$S A C J$ is a publication of the South African Institute of Computer Scientists and Information Technologists. ISSN 1015-7999 (print) ISSN 2313-7835 (online).
} 
the competencies of Business Process Owners and a business process owner competency framework was developed and discussed. The framework shows that business process owners require competencies in core business process management, strategic alignment, determining organizational goals, governance, documentation, training, and systemic thinking. 